\title{
Genetic evaluation of claw health traits accounting for potential preselection of cows to be trimmed
}

\author{
Iola Croué,${ }^{*} \dagger^{1}$ Freddy Fikse, $\ddagger$ Kjell Johansson, $\ddagger$ Emma Carlén, $\ddagger$ Gilles Thomas,§ Hélène Leclerc, $\dagger$ \\ and Vincent Ducrocq* \\ *INRA, and \\ †Institut de l'Elevage, UMR1313 Génétique Animale et Biologie Intégrative, 78352 Jouy-en-Josas Cedex, France \\ †Växa Sverige, Institutionen för Husdjursgenetik, Swedish University of Agricultural Sciences, Ulls väg 26, 75651 Uppsala, Sweden \\ §Institut de l'Elevage, Chambre Régionale d'Agriculture de Picardie, 19 bis rue Alexandre Dumas, 80096 Amiens Cedex 3, France
}

\section{ABSTRACT}

Claw lesions are one of the most important health issues in dairy cattle. Although the frequency of claw lesions depends greatly on herd management, the frequency can be lowered through genetic selection. A genetic evaluation could be developed based on trimming records collected by claw trimmers; however, not all cows present in a herd are usually selected by the breeder to be trimmed. The objectives of this study were to investigate the importance of the preselection of cows for trimming, to account for this preselection, and to estimate genetic parameters of claw health traits. The final data set contained 25,511 trimming records of French Holstein cows. Analyzed claw lesion traits were digital dermatitis, heel horn erosion, interdigital hyperplasia, sole hemorrhage circumscribed, sole hemorrhage diffused, sole ulcer, and white line fissure. All traits were analyzed as binary traits in a multitrait linear animal model. Three scenarios were considered: including only trimmed cows in a 7-trait model (scenario 1); or trimmed cows and contemporary cows not trimmed but present at the time of a visit (considering that nontrimmed cows were healthy) in a 7-trait model (scenario 2); or trimmed cows and contemporary cows not trimmed but present at the time of a visit (considering lesion records for trimmed cows only), in an 8-trait model, including a $0 / 1$ trimming status trait (scenario 3 ). For scenario 3 , heritability estimates ranged from 0.02 to 0.09 on the observed scale. Genetic correlations clearly revealed 2 groups of traits (digital dermatitis, heel horn erosion, and interdigital hyperplasia on the one hand, and sole hemorrhage circumscribed, sole hemorrhage diffused, sole ulcer, and white line fissure on the other hand). Heritabilities on

Received April 10, 2017.

Accepted July 12, 2017.

${ }^{1}$ Corresponding author: iola.croue@idele.fr the underlying scale did not vary much depending on the scenario: the effect of the preselection of cows for trimming on the estimation of heritabilities appeared to be negligible. However, including untrimmed cows as healthy caused bias in the estimation of genetic correlations. The use of a trimming status trait to account for preselection appears promising, as it allows consideration of the exhaustive population of cows present at the time a trimmer visited a farm without causing bias in genetic parameters.

Key words: claw lesion, genetic parameter, dairy cattle

\section{INTRODUCTION}

Claw lesions are one of the most important health issues in dairy cattle. They are quite frequent: in some studies more than $50 \%$ of cows show at least one lesion (e.g., Manske et al., 2002; Van der Linde et al., 2010; Van der Spek et al., 2013). Claw lesions have important consequences, both in terms of animal welfare and profitability of herds (Enting et al., 1997; Van der Waaij et al., 2005; Charfeddine and Pérez-Cabal, 2017). Reducing the prevalence of claw lesions is therefore of major interest in dairy farms. Claw health traits have a low but nonzero heritability, indicating a possibility of improvement through genetic selection, but also that the frequencies of claw disorders can mainly be reduced through proper herd management. Only a few countries have developed a national genetic evaluation for claw health traits (the Netherlands, Stoop et al., 2010; Denmark, Finland, and Sweden, Johansson et al., 2011; with a first evaluation in Sweden in 2006, Eriksson, 2006), and among these countries claw health phenotypes are often available only on a subset of cows: those scored by trimmers when they visit herds. As a consequence, a possible preselection effect of cows for trimming may affect genetic evaluations, particularly when the recording of claw health information is only 
recent and hence when the subset of phenotyped cows is small. However, the percentage of trimmed cows usually varies from one herd to another. Selecting only herds with high trimming proportions to ensure that almost all cows have been scored by a trimmer may allow for a reduction of the preselection but might also cause biases (van der Spek et al., 2013) because only herds with a specific herd management would be selected.

The objectives of the present study were to investigate the importance of the preselection of cows for trimming in Holstein herds in France, to compare the ways of accounting for this preselection and to assess their effect on the estimation of genetic parameters of claw health traits.

\section{MATERIALS AND METHODS}

\section{Data}

The phenotypes used were trimming information recorded from April 2014 to August 2016 on French Holstein cows by professional trimmers who followed the same training. The trimmers visited farms when called by farmers to trim their cows; the data recording itself was free of charge for the farmers. Trimming records from a cow were eliminated if the cow was not of the Holstein breed, was in lactation 4 or higher, had one or both parents unknown, was over 550 DIM at trimming, or was not registered for official milk recording. Only hind claw information was kept because front hooves were not often trimmed and showed fewer lesions than hind hooves. If for a given cow one of the hind claws was not scored, the cow record was eliminated. As most of the cows $(84 \%)$ had only one trimming information, only the first trimming record of each cow was kept. Records were also eliminated if the trimmer recorded information for less than 5 cows during a given visit.

In some parts of the study nontrimmed cows were also included; these were cows present in the herd when the trimmer came but not scored by the trimmer; the nontrimmed cows were edited using the same rules as the trimmed cows (lactation stage, parity...). As for the trimmed cows, only the first information was kept for nontrimmed cows (i.e., only one observation for the whole productive life, not per lactation), mainly because the number of repeated records was too low for a proper estimation of repeatability. The trimming date associated with nontrimmed cows was the date of the first trimming in the herd on which they were present.

The final data sets contained 25,511 cows when considering trimmed cows only and 57,399 cows when including also nontrimmed cows. The pedigree of the cows was traced back for 4 generations, leading to pedigree files of 85,040 animals when including only trimmed cows as phenotyped animals and 164,836 animals when including trimmed and nontrimmed cows.

\section{Traits}

The lesion traits considered were those defined according to the International Committee for Animal Recording (ICAR) claw health atlas (ICAR, 2015), with minor differences: sole hemorrhage circumscribed (SHC) was only recorded by the trimmers if it was present on the specific spot of the sole where a sole ulcer (SU) usually appears; SU was only recorded by the trimmers if it was present at its usual spot on the sole, whereas it can be recorded on any spot of the sole according to the ICAR atlas; and white line fissure (WLF) was recorded jointly with white line abscess (see Institut de l'Elevage, 2015 for details), whereas WLF are recorded as 2 different lesions in the ICAR atlas. Only traits with a prevalence of at least $5 \%$ in the data set were kept in this study: digital dermatitis (DD), heel horn erosion (HHE), interdigital hyperplasia (IH), SHC, sole hemorrhage diffused (SHD), SU, WLF, in which double sole was also included. The traits DD, HHE, and IH can be classified as infectious traits and SHC, SHD, SU, and WLF as noninfectious traits. A cow was given a score of 1 for a lesion if the lesion was observed by the trimmer, 0 if it was not. When nontrimmed cows were considered as healthy for all lesion traits, they were assigned a score of 0 for all lesions.

To assess the effect of the preselection of cows for trimming, a trimming status trait was created (see below). A cow's value for trimming status was 1 if she was trimmed and 0 otherwise.

\section{Statistical Analysis}

Genetic parameters for claw health traits were estimated fitting a multitrait linear animal model, using the restricted maximum likelihood methodology with the WOMBAT software (Meyer, 2007). The linear model was

$$
y_{i j k l}=\mu+h v_{i}+p_{j}+s_{k}+a_{l}+\varepsilon_{i j k l},
$$

where $y_{i j k l}$ is the observed performance for DD, HHE, $\mathrm{IH}, \mathrm{SHC}, \mathrm{SHD}, \mathrm{SU}$, or WLF; $\mu$ is the general mean; $h v_{i}$ is the herd-date of visit contemporary group; $p_{j}$ is the parity of the cow; $s_{k}$ is the lactation stage of the cow (1-50 d, 51-100 d, 101-150 d, 151-200 d, 201-250 d, 251-300 d, 301-350 d, 351-400 d, and 401-550 d); $a_{l}$ is the animal's additive genetic value treated as a random effect with a variance-covariance matrix proportional 
Table 1. Prevalence (\%) of claw lesions on the whole population of trimmed cows and in low-trimming (less than $30 \%$ of cows trimmed), moderate-trimming (31 to 60\%), and high-trimming (more than 60\%) herds

\begin{tabular}{lcccc}
\hline Lesion & Whole population & Low-trimming herds & Moderate-trimming herds & High-trimming herds \\
\hline Digital dermatitis (DD) & 29 & 33 & 33 & 26 \\
Heel horn erosion (HHE) & 53 & 42 & 46 & 9 \\
Interdigital hyperplasia (IH) & 8 & 10 & 1 & 7 \\
Sole hemorrhage circumscribed (SHC) & 16 & 3 & 35 & 19 \\
Sole hemorrhage diffused (SHD) & 43 & 10 & 8 & 6 \\
Sole ulcer (SU) & 7 & 14 & 74 & 74 \\
White line fissure (WLF) & 14 & 77 & 7 & 87 \\
At least one lesion & 82 & 14 & 4 \\
Proportion of lame cows & 6 & & \\
\hline
\end{tabular}

to the pedigree-based relationship matrix; and $\varepsilon_{i j k l}$ is the random residual.

\section{Investigation of the Effect of Preselection}

To investigate the influence of cow preselection for trimming, 3 different scenarios were conducted using the same model: scenario 1 was a 7 -trait (one per lesion) analysis of a data set containing trimmed cows only, scenario 2 was a 7 -trait (one per lesion) analysis of a data set containing both trimmed and nontrimmed cows, with nontrimmed cows considered healthy for all the lesion traits, scenario 3 was an 8 -trait (1 per lesion plus trimming status) analysis of a data set where only trimmed cows had records for the lesion traits. To compare heritability estimates between scenarios independent of disease prevalence, heritabilities were converted to an underlying scale, as described by Dempster and Lerner (1950).

To further investigate the effect of considering nontrimmed cows as healthy for all lesion traits, herds were randomly split into 2 groups. In group 1, only trimmed cows were considered (as in scenario 1); in group 2, nontrimmed cows were included and considered healthy (as in scenario 2). Group 1 included 11,441 cows from 445 herds, and group 2 included 30,603 cows (14,070 of which were trimmed cows) from 502 herds. The same lesions in the herds in groups 1 and 2 were considered as different traits (e.g., DD group 1 and DD group 2) and analyzed jointly in a bivariate analysis to know if considering nontrimmed cows as healthy led to evaluating genetically different traits.

A wide variety of trimming practices (proportions) was detected in the data set: some herds trimmed only a low proportion of their cows (below 10\%) and others trimmed almost all their cows (more than 90\%). To assess the effect of such heterogeneity, herds were split into 3 groups: low trimming (trimming less than $30 \%$ of the cows present), moderate trimming (trimming 31 to $60 \%$ of the cows), or high trimming (trimming more than $60 \%$ of the cows). The low-trimming group con- sisted of 21,341 cows (including 4,043 trimmed cows), from 358 herds, the moderate-trimming group 19,653 cows (including 8,312 trimmed) from 325 herds, and the high-trimming group 16,405 cows (including 13,156 trimmed) from 264 herds.

Lesions in low-trimming and high-trimming herds were considered as different traits (e.g., DD low-trimming and DD high-trimming) and analyzed along with trimming status in trivariate analyses.

\section{RESULTS}

\section{Prevalences}

In the whole population of trimmed cows, $82 \%$ of the cows had at least one lesion (Table 1). The HHE and SHD were the most frequent lesions, with prevalences of 53 and $43 \%$, respectively. The least frequent lesion was SU, with a prevalence of $7 \%$. In high-trimming herds, a higher proportion of cows had at least one lesion than in low-trimming herds. Most lesions were more frequent in high-trimming herds than in low-trimming herds, except for DD, IH, and SU.

\section{Genetic Parameters}

In scenario 1 (trimmed cows only), heritability estimates were generally low (between 0.02 and 0.08; Table 2 ); they were the highest for DD and IH and the lowest for SHC and SHD. Genetic correlations varied widely depending on the traits considered, from -0.37 (between SHC and DD) to 0.79 (between SHC and SU). In general, genetic correlations among lesions of the same group were moderate to high and positive (except for the correlation between SHD and WLF, which was close to 0 ); they ranged from 0.07 to 0.79 among noninfectious traits and from 0.60 to 0.74 among infectious traits. In general, genetic correlations between lesions of the 2 different groups were not significantly different from zero, due to large standard errors; they ranged from -0.37 to 0.20 . 
Table 2. Genetic parameters in the whole population from scenario 1 (with only trimmed cows) ${ }^{1}$

\begin{tabular}{|c|c|c|c|c|c|c|c|}
\hline Lesion $^{2}$ & \multicolumn{3}{|c|}{ Infectious trait } & \multicolumn{4}{|c|}{ Noninfectious trait } \\
\hline $\begin{array}{l}\mathrm{DD} \\
\mathrm{HHE} \\
\text { IH } \\
\text { SHC } \\
\text { SHD } \\
\text { SU } \\
\text { WLF }\end{array}$ & $0.08(0.01)$ & $\begin{array}{l}0.66(0.10) \\
0.04(0.01)\end{array}$ & $\begin{array}{l}0.74(0.06) \\
0.60(0.11) \\
0.08(0.01)\end{array}$ & $\begin{array}{r}-0.37(0.13) \\
-0.20(0.17) \\
-0.16(0.14) \\
0.02(0.01)\end{array}$ & $\begin{array}{r}-0.23(0.15) \\
-0.19(0.18) \\
-0.26(0.15) \\
0.54(0.18) \\
0.02(0.01)\end{array}$ & $\begin{array}{r}0.06(0.11) \\
0.20(0.13) \\
-0.01(0.11) \\
0.79(0.12) \\
0.22(0.17) \\
0.05(0.01)\end{array}$ & $\begin{array}{r}-0.14(0.11) \\
-0.07(0.13) \\
-0.07(0.11) \\
0.44(0.15) \\
0.07(0.17) \\
0.58(0.11) \\
0.06(0.01)\end{array}$ \\
\hline
\end{tabular}

${ }^{1}$ Heritabilities are on the diagonal, genetic correlations above, SE in parentheses.

${ }^{2} \mathrm{DD}=$ digital dermatitis; HHE = heel horn erosion; $\mathrm{IH}=$ interdigital hyperplasia; $\mathrm{SHC}=$ sole hemorrhage circumscribed; SHD = sole hemorrhage diffused; $\mathrm{SU}=$ sole ulcer; $\mathrm{WLF}=$ white line fissure.

When including nontrimmed cows considered as healthy for all lesion traits (scenario 2) in the data set, heritability estimates were lower (0.01 to 0.05 , Table 3 ). Genetic correlations were all identical or higher than those estimated in scenario 1 , particularly for correlations between noninfectious traits and infectious traits $(+0.15$ to +0.74 in scenario 2 compared with scenario $1)$. The highest difference was observed for the correlation between HHE and SHD.

When including nontrimmed cows in the analysis together with a trimming status and only considering lesion records for trimmed cows (scenario 3), heritabilities of the 7 lesion traits were very similar to those estimated with scenario 1 (slightly higher for infectious traits; Table 4). Trimming status had a low but nonzero heritability. Genetic correlations were in the same range (identical to slightly higher) than those estimated in scenario 1 . The highest difference was observed for the correlation between HHE and SHD $(+0.22$ in scenario 3 compared with scenario 1 ). The genetic correlations were closer to those obtained with scenario 1 than scenario 2. Genetic correlations between lesion traits and trimming status varied from close to zero to moderate except for HHE, which had a strong genetic correlation with trimming status. Genetic correlations were higher for infectious than noninfectious traits.

Despite low heritabilities, claw lesion traits showed genetic variability as their coefficients of genetic variation varied from 0.13 (SHD) to 0.95 (IH) and their genetic standard deviations from 0.05 (SHC and SHD) to 0.12 (DD; Table 5).

\section{Genetic Correlations for the Same Trait in Scenario 1 and 2}

The genetic correlation between lesions from bivariate analysis of 2 groups of herds, where nontrimmed cows were included and considered healthy in just one group, were close or equal to 1 , with the exception of SHD (Table 6). For SHD it was lower (0.74), but with a high standard error (0.32).

\section{Genetic Correlations for the Same Trait in Low-Trimming and High-Trimming Herds}

The genetic correlations between lesions analyzed together with trimming status from trivariate analysis of 2 groups of herds, where one group consisted of low-

Table 3. Genetic parameters in the whole population from scenario 2 (with trimmed and nontrimmed cows, nontrimmed cows considered healthy $)^{1}$

\begin{tabular}{|c|c|c|c|c|c|c|c|}
\hline Lesion $^{2}$ & \multicolumn{3}{|c|}{ Infectious trait } & \multicolumn{4}{|c|}{ Noninfectious trait } \\
\hline $\begin{array}{l}\text { DD } \\
\text { HHE } \\
\text { IH } \\
\text { SHC } \\
\text { SHD } \\
\text { SU } \\
\text { WLF }\end{array}$ & $0.05(0.01)$ & $\begin{array}{l}0.75(0.06) \\
0.03(0.01)\end{array}$ & $\begin{array}{l}0.79(0.05) \\
0.67(0.07) \\
0.05(0.01)\end{array}$ & $\begin{array}{l}0.10(0.12) \\
0.32(0.12) \\
0.15(0.12) \\
0.01(0.00)\end{array}$ & $\begin{array}{l}0.30(0.12) \\
0.55(0.11) \\
0.19(0.12) \\
0.67(0.13) \\
0.01(0.00)\end{array}$ & $\begin{array}{l}0.33(0.09) \\
0.46(0.09) \\
0.19(0.10) \\
0.88(0.08) \\
0.52(0.12) \\
0.03(0.00)\end{array}$ & $\begin{array}{l}0.04(0.10) \\
0.15(0.11) \\
0.08(0.10) \\
0.44(0.13) \\
0.17(0.14) \\
0.60(0.09) \\
0.03(0.01)\end{array}$ \\
\hline
\end{tabular}

${ }^{1}$ Heritabilities are on the diagonal, genetic correlations above, SE in parentheses.

${ }^{2} \mathrm{DD}=$ digital dermatitis; HHE = heel horn erosion; $\mathrm{IH}=$ interdigital hyperplasia; $\mathrm{SHC}=$ sole hemorrhage circumscribed; $\mathrm{SHD}=$ sole hemorrhage diffused; $\mathrm{SU}=$ sole ulcer; $\mathrm{WLF}=$ white line fissure. 
Table 4. Genetic parameters in the whole population from scenario 3 [with trimmed and nontrimmed cows, using trimming status (trim) $]^{1}$

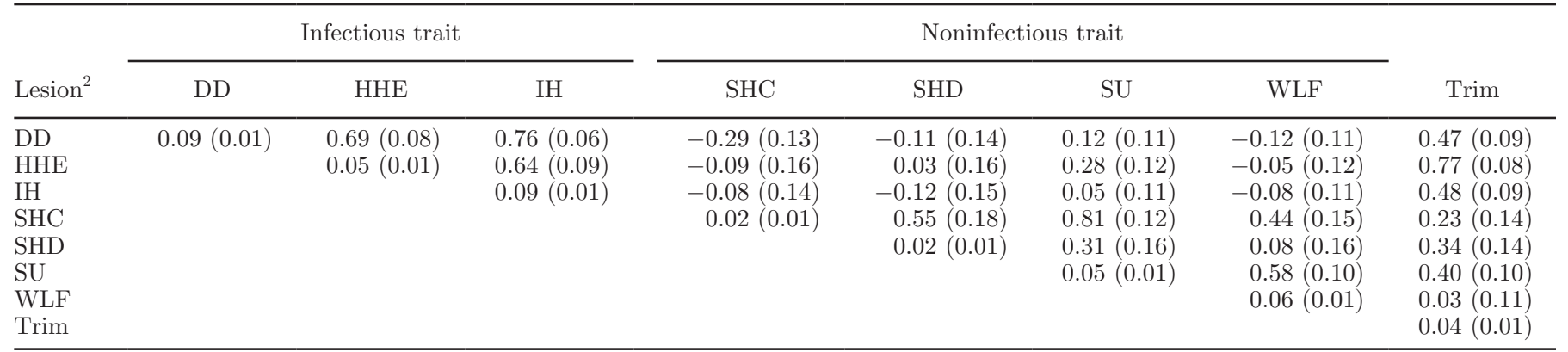

${ }^{1}$ Heritabilities are on the diagonal, genetic correlations above, SE in parentheses.

${ }^{2} \mathrm{DD}=$ digital dermatitis; HHE = heel horn erosion; $\mathrm{IH}=$ interdigital hyperplasia; SHC = sole hemorrhage circumscribed; SHD = sole hemorrhage diffused; $\mathrm{SU}=$ sole ulcer; $\mathrm{WLF}=$ white line fissure.

trimming herds and the other of high-trimmings herds, were close or equal to 1, with the exception of SHD and DD (Table 7). For SHD and DD, genetic correlations were lower (equal to 0.54 and 0.68 , respectively), with SHD showing a large standard error (0.62).

\section{DISCUSSION}

\section{Prevalences}

Lesion prevalences were quite high, and in the whole population, only $18 \%$ of trimmed cows did not show any lesions. Although not unusual, these values were in the high range of what has been reported in similar studies: for Swedish dairy cows, Manske et al. (2002) reported that $63 \%$ of the cows showed at least one lesion on hind hooves, with similar prevalences as ours for some of the most severe lesions (DD, SU, and WLF) but much lower for others (hemorrhages, IH). For Dutch dairy cows, van der Waaij et al. (2005) reported that more than $70 \%$ of the cows had at least one claw disorder. For Holstein cows, van der Spek et al. (2013) reported that $55 \%$ of the cows had at least one claw disorder, with again some lesion prevalences quite similar to ours (for WLF, IH, and SU) and some very

Table 5. Genetic SD and coefficients of genetic variation in the whole population from scenario 3 (with trimmed and nontrimmed cows, using trimming status)

\begin{tabular}{lcc}
\hline Lesion $^{1}$ & Genetic SD & Coefficient of genetic variation \\
\hline DD & 0.12 & 0.41 \\
HHE & 0.08 & 0.15 \\
IH & 0.08 & 0.95 \\
SHC & 0.05 & 0.32 \\
SHD & 0.05 & 0.13 \\
SU & 0.06 & 0.78 \\
WLF & 0.08 & 0.56 \\
\hline
\end{tabular}

${ }^{1} \mathrm{DD}=$ digital dermatitis; HHE = heel horn erosion; $\mathrm{IH}=$ interdigital hyperplasia; $\mathrm{SHC}=$ sole hemorrhage circumscribed; $\mathrm{SHD}=$ sole hemorrhage diffused; $\mathrm{SU}=$ sole ulcer; $\mathrm{WLF}=$ white line fissure. different (combined DD-HHE trait, sole hemorrhages). Cows in our study had more lesions than in most of the other studies, maybe due to a difference in claw trimmer training, lesion definition, or exposure to risk factors. It may also be linked to the quite recent start of data collection: data might not yet be representative of the whole French population.

High-trimming herds had a lower proportion of healthy cows than low-trimming herds. This may indicate that high-trimming herds experience more risk factors for claw lesions and that their high trimming proportion is a necessity. It could also reflect a general poor level of claw health in the population, if these herds practice preventive trimming. Either way, it seems very unlikely that all nontrimmed cows $55 \%$ of the population) can safely be considered to be free from any claw lesion. Moreover, this clearly highlights that high-trimming herds are not necessarily representative of the whole population: they can reflect specific managements or environments.

Because high-trimming herds contained fewer trimmed cows without lesions, they generally showed higher lesion prevalences than low-trimming herds, except for DD, IH, and SU. These lesions can develop into more visible disorders (lameness notably) than

Table 6. Genetic correlations between equivalent lesion traits in scenario 1 (trimmed cows only) and scenario 2 (nontrimmed cows considered healthy), SE in parentheses

\begin{tabular}{lc}
\hline Lesion $^{1}$ & Genetic correlation \\
\hline DD & $0.93(0.06)$ \\
HHE & $0.99(0.11)$ \\
IH & $0.99(0.10)$ \\
SHC & $0.98(0.20)$ \\
SHD & $0.74(0.32)$ \\
SU & $1.00(0.11)$ \\
WLF & $1.00(0.10)$ \\
\hline
\end{tabular}

${ }^{1} \mathrm{DD}=$ digital dermatitis; $\mathrm{HHE}=$ heel horn erosion; $\mathrm{IH}=$ interdigital hyperplasia; $\mathrm{SHC}=$ sole hemorrhage circumscribed; $\mathrm{SHD}=$ sole hemorrhage diffused; $\mathrm{SU}=$ sole ulcer; $\mathrm{WLF}=$ white line fissure. 
the others (except WLF at severe stages), which could explain their higher prevalences in low-trimming herds: cows with more severe issues are given priority for trimming when only a low proportion of cows are trimmed. This was consistent with the observation that a larger proportion of lame cows was reported in low-trimming than in high-trimming herds.

\section{Preselection of Cows for Trimming}

Scenarios 1 and 3 led to almost identical heritability estimates. In contrast, scenario 2 resulted in lower heritability estimates. However, as heritability estimates are frequency-dependent when analyzing binary variables with a linear model, the lower heritability in scenario 2 is related to a lower frequency of claw lesions when considering all nontrimmed cows healthy for all lesions. Heritabilities on the underlying scale, which measure heritabilities independently from frequency, did not vary much between all analyses (results not shown). Thus, the effect of the preselection of cows for trimming on the estimation of heritabilities appeared to be negligible. The results of van der Spek et al. (2013) and Malchiodi et al. (2015) are in agreement with these findings.

In scenario 3, trimming status had a low but nonzero heritability: there is a genetic background for cows to be trimmed. Genetic correlations between lesion traits and trimming status varied widely and were generally moderate: this suggests that jointly evaluating lesion traits and trimming status is beneficial. It also suggests that there is no systematic association between the presence of a lesion and the fact that a cow is trimmed. Van der Spek et al. (2013) also found a low but different from zero (higher than our estimate, on the observed and underlying scale) heritability for trimming status (0.09). Their genetic correlation estimates between lesion traits and trimming status were generally also

Table 7. Genetic correlations between equivalent lesion traits in lowtrimming and high-trimming herds, SE in parentheses

\begin{tabular}{lc}
\hline Lesion $^{1}$ & Genetic correlation \\
\hline DD & $0.68(0.14)$ \\
HHE & $1.00(0.17)$ \\
IH & $0.86(0.12)$ \\
SHC & $0.96(0.62)$ \\
SHD & $0.54(0.62)$ \\
SU & $0.99(0.27)$ \\
WLF & $0.86(0.16)$ \\
\hline
\end{tabular}

${ }^{1} \mathrm{DD}=$ digital dermatitis; HHE = heel horn erosion; $\mathrm{IH}=$ interdigital hyperplasia; $\mathrm{SHC}=$ sole hemorrhage circumscribed; $\mathrm{SHD}=$ sole hemorrhage diffused; $\mathrm{SU}=$ sole ulcer; $\mathrm{WLF}=$ white line fissure. moderate. However, they were quite different for some traits (sole hemorrhages mainly), which might be due to differences in lesion definitions and the fact that we used a full multitrait model, with all lesions and trimming status, rather than multiple bivariate models analyzing one lesion trait and trimming status.

Genetic correlations among traits were either identical or slightly higher (mainly between infectious and noninfectious traits) in scenario 3 compared with 1: including contemporary nontrimmed cows using trimming status did not change genetic correlation estimates. In scenario 2, however, genetic correlations among noninfectious traits and among infectious traits were similar to those of scenario 1 but genetic correlations between noninfectious and infectious traits were much higher, leading to no clear distinction between the 2 trait groups. These results were expected as in scenario 2 all nontrimmed cows had the same phenotype (no lesion) for all traits. Hence, considering nontrimmed cows as healthy for the evaluation of claw health traits may have caused a bias in the estimation of genetic correlations. It would be interesting to see similar comparisons on larger data sets. Machioldi et al. (2017) conducted a similar study and did not observe large differences in genetic correlations among lesion traits between scenarios without nontrimmed cows and with nontrimmed cows considered healthy. This difference may partly be due to the fact that they had a higher proportion of trimmed cows ( $76 \%$ of trimmed cows, $44 \%$ in our case).

Our results indicate that the influence of the preselection of cows for trimming on the estimation of heritabilities is negligible, in accordance with van der Spek et al. (2013) and Malchiodi et al. (2015). There were, however, some consequences of the inclusion of nontrimmed cows on the estimation of genetic correlations if they were considered healthy for all lesions. Nevertheless, when lesions were considered as different traits in scenario 1 and 2 and analyzed in a bivariate analysis, they showed very high genetic correlations. That is, despite the inclusion of nontrimmed cows as healthy, lesion traits evaluated in scenario 1 or scenario 2 were the same. The inclusion of nontrimmed cows based on the use of a supplementary trimming status trait appeared, in our case, to be an interesting way of dealing with the preselection of cows for trimming. This allows taking into account the preselection information as all cows present on the herd at the date of trimming were considered in the evaluation. It brings information for the evaluation of lesion traits as it has moderate to high genetic correlations with most of them. Furthermore, it does not require any dubious hypothesis and represents a negligible computational cost in a genetic evaluation. 


\section{Genetic Parameters}

Heritability estimates were low for all analyses: claw lesion traits can be improved by selection, but with a low accuracy. These low values were not surprising: claw lesions are known to be strongly influenced by housing conditions even though they have a genetic component. Other studies reported comparable heritabilities (Johansson et al., 2011; van der Spek et al., 2013, Malchiodi et al., 2015). However, despite low heritabilities, coefficients of genetic variation indicate the existence of genetic variability for genetic selection.

Genetic correlations varied widely; they were generally lower between groups of traits (infectious vs. noninfectious) than within groups, which underlines the existence of 2 genetically distinct groups of claw lesions. This is confirmed by other studies (van der Linde et al., 2010; Johansson et al., 2011; van der Spek et al., 2013); even though individual claw lesion definitions might differ, the distinction between noninfectious and infectious traits remains. The highest correlation was found between SHC and SU, which was consistent with the fact that $\mathrm{SHC}$ is known to be a precursor of SU.

Most studies do not differentiate SHC and SHD. However, it is clear based on our results that they are different traits: their genetic correlation was quite strong but far from 1 (0.55) and they had very different genetic correlations with other noninfectious traits.

All of the genetic parameter estimates had quite high standard errors, likely due to the relatively low number of phenotypes. These results should have a higher accuracy when more data are added to the evaluation.

\section{Herds with Different Trimming Proportions}

The data set included herds showing extremely various trimming proportions. This could reflect different managements or different degrees of risk for the appearance of lesions. It raised the question of whether cows from herds with very different trimming proportions could all be treated the same way and whether traits could be considered identical traits in low-trimming herds and high-trimming herds. Furthermore, herds with very different trimming proportions (low-trimming herds and high-trimming herds) might have different strategies in the way they select cows for trimmings.

When lesions measured in low-trimming herds and high-trimming herds were considered as different traits, most of the traits had a very high genetic correlation between their 2 environments, suggesting that they were almost identical traits. Only SHD and DD had moderate genetic correlations between their lowtrimming and high-trimming versions, but with a large standard error for SHD. For simplicity, we decided to treat all traits the same way and SHD and DD were also treated as identical traits in various trimming intensity herds. Extra analyses were made to ensure that this hypothesis did not create bias in the evaluation: genetic and residual variances of different trimming proportion traits were compared and showed only little differences (results not shown).

\section{CONCLUSIONS}

Claw health has a genetic component and hence can be improved by selection. Heritability estimates for claw lesion traits were low, indicating that environmental factors have a larger influence than genetics. Genetic correlations revealed 2 genetic groups for claw lesions: infectious (DD, HHE, and $\mathrm{IH}$ ) and noninfectious (SHC, SHD, WLF, and SU) lesions. Genetic correlations between the 2 groups were close to zero and among the 2 groups they were generally moderate to high. Combining data from herds with very different trimming proportions and very different prevalences did not present a problem: genetically, traits could be considered as identical in those different environments. The problem of the preselection of cows for trimming and the choice of a way of dealing with this preselection can have an important effect on the estimation of genetic parameters, particularly on the genetic correlations between infectious and noninfectious traits. The effect of cow preselection was, however, negligible on the estimation of heritabilities. In our case, the use of a trimming status trait to account for preselection appears promising, as it allows considering the exhaustive population of cows present at the time a trimmer visited a farm without causing bias in genetic parameters.

\section{ACKNOWLEDGMENTS}

The authors acknowledge APIS-GENE (Paris, France) for financial support (partly through the POD2 project), the claw trimmers for their continuous work on gathering data, François Guillaume (EVOLUTION, France), Luc Manciaux (Bretagne Conseil Elevage Ouest, France), Jean Bernard Davière (CLASEL, France), and Luc Voidey (Elistest, France) for granting access to the phenotypes and managing the database and Nordic Cattle Genetic Evaluation for involving part of the Växa Sverige (Uppsala, Sweden) team in this project. This study was conducted in the Mixed Technology Unit e-BIS (Jouy-en-Josas, France) and is part of the Genosante project, managed by Maëlle Philippe (EVOLUTION, France) and led by EVOLUTION (Plancoët, France). 


\section{REFERENCES}

Charfeddine, N., and M. A. Pérez-Cabal. 2017. Effect of claw disorders on milk production, fertility, and longevity, and their economic impact in Spanish Holstein cows. J. Dairy Sci. 100:653-665. https:// doi.org/10.3168/jds.2016-11434.

Dempster, E. R., and I. M. Lerner. 1950. Heritability of threshold characters. Genetics 35:212.

Enting, H., D. Kooij, A. A. Dijkhuizen, R. B. M. Huirne, and E. N Noordhuizen-Stassen. 1997. Economic losses due to clinical lameness in dairy cattle. Livest. Prod. Sci. 49:259-267. https://doi.org/ 10.1016/S0301-6226(97)00051-1.

Eriksson, J.-A. 2006. Swedish sire evaluation of hoof diseases based on hoof trimming records. Interbull Bull. 35:49-52.

Institut de l'Elevage. 2015. Les lésions d'onglons des bovins. Accessed Mar. 11, 2016. http://www.formation-continue.theodore-monod .educagri.fr/fileadmin/user_upload/pdf/parage/definition_lesions _d_onglons_des_bovins_2015.pdf.

International Committee for Animal Recording (ICAR). 2015. ICAR claw health atlas. Accessed May 17, 2016. http://www.icar.org/ documents/icar_claw_health_atlas.pdf.

Johansson, K., J.-A. Eriksson, U. Sander Nielsen, J. Pösö, and G. P. Aamand. 2011. Genetic evaluation of claw health in Denmark, Finland and Sweden. Interbull Bull. 44:224-228.

Machioldi, F., A. Koeck, S. Mason, A. M. Christen, D. F. Kelton, F. S. Schenkel, and F. Miglior. 2017. Genetic parameters for hoof health traits estimated with linear and threshold models using alternative cohorts. J. Dairy Sci. 100:2828-2836.
Malchiodi, F., A. Koeck, N. Chapinal, M. Sargolzai, A. Fleming, D. F. Kelton, F. S. Schenkel, and F. Miglior. 2015. Genetic analyses of hoof lesions in Canadian Holsteins using an alternative contemporary group. Interbull Bull. 49:64-68.

Manske, T., J. Hultgren, and C. Bergsten. 2002. Prevalence and interrelationships of hoof lesions and lameness in Swedish dairy cows. Prev. Vet. Med. 54:247-263. https://doi.org/10.1016/S0167 $-5877(02) 00018-1$

Meyer, K. 2007. WOMBAT-A tool for mixed model analyses in quantitative genetics by restricted maximum likelihood. J. Zhejiang Univ. Sci. B 8:815-821.

Stoop, W. M., G. de Jong, M. L. van Pelt, and C. van der Linde. 2010. Implementation of a claw health index in the Netherlands. Interbull Bull. 42:95-99.

van der Linde, C., G. Jong, E. Koenen, and H. Eding. 2010. Claw health index for Dutch dairy cattle based on claw trimming and conformation data. J. Dairy Sci. 93:4883-4891. https://doi.org/10 $.3168 /$ jds.2010-3183.

van der Spek, D., J. A. M. Arendonk, A. A. A. Vallée, and H. Bovenhuis. 2013. Genetic parameters for claw disorders and the effect of preselecting cows for trimming. J. Dairy Sci. 96:6070-6078. https://doi.org/10.3168/jds.2013-6833.

van der Waaij, E. H., M. Holzhauer, E. Ellen, C. Kamphuis, and G. de Jong. 2005. Genetic parameters for claw disorders in Dutch dairy cattle and correlations with conformation traits. J. Dairy Sci 88:3672-3678. https://doi.org/10.3168/jds.S0022-0302(05)73053 -8 . 